\title{
Critical Role for Ventral Tegmental Glutamate in Preference for a Cocaine-Conditioned Environment
}

\author{
Glenda C Harris' and Gary Aston-Jones*,' \\ 'Department of Psychiatry, University of Pennsylvania, Philadelphia, PA, USA
}

\begin{abstract}
Cocaine administration induces glutamatergic activation within the mesolimbic-accumbens system. This activation has been linked to the behavioral effects of cocaine and recently to the induction of long-term potentiation in dopamine neurons within the ventral tegmental area (VTA). We sought to determine if glutamate receptor activation is also crucial to the development of a conditioned place preference (CPP) to cocaine's rewarding effects. Two groups of rats were given intra-VTA injections of either vehicle or a combination of NMDA ( $N$-methyl-D-aspartate) and AMPA ( $\alpha$-amino-3-hydroxy-5-methyl-4-isoxazolepropionic acid) receptor antagonists (AP5 $0.24 \mathrm{nmol}$ plus CNQX $0.12 \mathrm{nmol}$ per side) prior to each cocaine place-conditioning trial. Microinjections of the glutamate antagonists completely blocked the development of a cocaine CPP when given within, but not when given outside of, the VTA. These data indicate that glutamatergic activity in the VTA may be crucial for learning to associate environmental stimuli with cocaine exposure. Neuropsychopharmacology (2003) 28, 73-76. doi: I 0.1038/sj.npp. I 3000 I I
\end{abstract}

Keywords: cocaine; glutamate; dopamine; place conditioning; ventral tegmental area; NMDA receptor antagonist; AMPA receptor antagonist

\section{INTRODUCTION}

Drug addiction has long been thought to involve learning and plasticity within the mesocortical limbic system (Wolf, 1998; Parkinson et al, 2000; Hyman et al, 2001). Glutamate transmission has been implicated in most forms of learning and plasticity (Pennartz et al, 2000). Cocaine causes glutamate release in the ventral tegmental area (VTA) (Kalivas and Duffy, 1995) and alters the responsiveness of glutamate receptors in the VTA after repeated exposure (Zhang et al, 1997). Recently, cocaine has been shown to produce long-term potentiation in VTA dopamine neurons via modifications in glutamatergic synaptic transmission (Ungless et al, 2001).

We hypothesized that conditioning of cocaine-related cues may involve glutamate transmission in the VTA. Previous studies showed that systemic administration of glutamate antagonists blocked cocaine-induced locomotor sensitization (Wolf and Jeziorski, 1993; Karler et al, 1994), acquisition of self-administration (Schenk et al, 1993) and conditioned place preference (Cervo and Samanin, 1995; Kim et al, 1996). In addition, intra-VTA injections of NMDA antagonists have been reported to block locomotor sensitization to both cocaine (Kalivas and Alesdatter, 1993)

\footnotetext{
*Correspondence: G Aston-Jones, Department of Psychiatry, University of Pennsylvania, VAMC (I5I) Room A520, University and Woodland Avenues, Philadelphia, PA 19104, USA, Tel: +215-5735200, Fax: +215-573-5202, E-mail: gaj@mail.med.upenn.edu Received 19 February 2002; revised 9 May 2002; accepted 14 May 2002
}

and amphetamine (Cador et al, 1999). Although it has been suggested that glutamate transmission in the VTA is involved in the addictive properties of cocaine (Ungless et al, 2001), the role of this input in operant behavior has been relatively unexplored. Here we provide the first evidence that glutamate release in the VTA may be essential for the conditioning of preference to cocaine-associated cues.

\section{METHODS}

\section{Subjects}

Male Sprague-Dawley rats (200-250 g; Harlan, Indianapolis, IN) were used in all experiments $(n=33)$. Rats were grouphoused in accordance with $\mathrm{NIH}$ guidelines on a 12-h light/ dark cycle with food and water available ad libitum. All animal procedures were approved by the animal care and use committees of the Philadelphia Veterans Administration Medical Center and the University of Pennsylvania.

\section{Drugs}

Cocaine $\mathrm{HCl}$ powder, provided by the National Institute on Drug Abuse, was dissolved in sterile saline and administered via intraperitoneal (i.p.) injection. The AMPA ( $\alpha$-amino-3-hydroxy-5-methyl-4-isoxazolepropionic acid) receptor antagonist CNQX (6-cyano-7-nitroquinoxaline-2,3-dione) and the NDMA ( $N$-methyl-D-aspartate) receptor antagonist D-AP5 (D(-)-2-amino-5-phosphonopentanoic acid), purchased from Tocris (Ellisville, MO), were dissolved in artificial cerebral spinal fluid (aCSF). 


\section{Intracerebral Injections}

Under sodium pentobarbital anesthesia, rats were implanted with bilateral chronic indwelling guide cannulae aimed $2 \mathrm{~mm}$ above the VTA (AP -5.3, ML +2.5, DV - 7.5; Paxinos and Watson, 1998). Cannulae (26 gauge) were angled $10^{\circ}$ (dorsolateral to ventromedial). The tips of inner injection cannulae (30 gauge) extended $2 \mathrm{~mm}$ below the guide cannulae into the injection sites. Control injections were made $2 \mathrm{~mm}$ above the VTA (AP $-5.3, \mathrm{ML}+2.5$, $\mathrm{DV}-5.5)$. Animals were given 1 week to recover from surgery before receiving place conditioning.

\section{Conditioned Place Preference Procedure}

Conditioning and testing occurred in a Plexiglas apparatus that consisted of two distinct compartments or chambers that could be separated by a Plexiglas divider. Each compartment was equipped with photocells to log time and activity automatically (MED Associates). One compartment had a grid floor with black walls, and the second compartment had a mesh floor with black and white stripes on the walls. During the conditioning procedures, three groups of rats were treated with cocaine and three groups were treated with saline only, as follows. On the first day, rats in all groups were allowed to explore freely all of the apparatus for $15 \mathrm{~min}$, and the amount of time spent in each compartment was recorded. None of the animals had an initial bias for either compartment, and each was randomly assigned to a compartment for cocaine conditioning in a balanced design. Conditioning began 4 days after this preconditioning day. On each of the next 3 days, groups 1-3 were given injections of either saline or cocaine $(10 \mathrm{mg} / \mathrm{kg})$ and were confined to the assigned compartment for $30 \mathrm{~min}$. Cocaine and saline sessions were alternated between the morning and afternoon. Rats given cocaine while in one chamber in the morning were given saline in the opposite chamber in the afternoon, and on subsequent days received saline in the morning and cocaine in the afternoon. In addition, group 1 received bilateral vehicle injections into the VTA (aCSF, $0.3 \mu$ l per side; $n=7$ rats), group 2 received similar intra-VTA injections of a glutamate antagonist cocktail (AP5 $0.24 \mathrm{nmol}$ plus CNQX $0.12 \mathrm{nmol}, 0.3 \mu \mathrm{l}$ per side; $n=6$ rats), and group 3 received the same antagonist cocktail as group 2 but injected $2 \mathrm{~mm}$ dorsal to the VTA ( $n=6$ rats). In all three groups, microinjections were made $15 \mathrm{~min}$ prior to each cocaine-conditioning trial. Groups 4-6 received systemic saline injections before being placed in both environments, and the same CPP procedure was followed as described above. Rats in group 4 received bilateral injections of the above glutamate antagonist cocktail into the VTA $(n=4)$, rats in group 5 received bilateral vehicle injections into the VTA $(n=6)$, and rats in group 6 received bilateral injections of the glutamate antagonist cocktail outside of the VTA $(n=4) 15 \mathrm{~min}$ prior to confinement in one chamber. The chamber paired with the intracerebral microinjections was counterbalanced among subjects. All animals were given a preference test with the divider removed 4 days after conditioning; the amount of time spent in each chamber was recorded for $15 \mathrm{~min}$.

\section{Histology and Data Analyses}

Animals were killed with an overdose of sodium pentobarbital. Injections of pontine sky blue $(0.5 \mu \mathrm{l})$ were made at the intracerebral injection sites to allow subsequent histological confirmation. Place-conditioning data were analyzed by calculating the time spent in the cocainepaired chamber (or intracerebral microinjection-paired chamber for groups 4-6) minus the time spent in the other chamber. The resulting difference score was compared between groups using one-way analysis of variance. In addition, a within-group measurement of conditioned place preference was assessed by comparing the difference in time spent in the cocaine-paired (or intracerebral microinjection-paired) and saline-paired side preconditioning $v s$ postconditioning. Where necessary, post hoc analysis was carried out with a Newman-Keuls test.

\section{RESULTS AND DISCUSSION}

As shown in Figure 1, the glutamate antagonists completely blocked the acquisition of the cocaine place preference when administered into histologically confirmed VTA sites $(p<0.01)$. In contrast, neither antagonist administration outside of the VTA nor vehicle injections inside the VTA significantly affected cocaine conditioning (Figure 1). Antagonist injections into the VTA of animals that received no cocaine conditioning produced place preference, not aversion $(\mathrm{F}(1,6)=125, p<0.001$; Figure 1$)$. This indicates that the attenuation of cocaine-associated preference by the antagonists was not because of an aversive effect of the antagonists themselves. The antagonist-induced place preference was specific for sites in the VTA and not because of

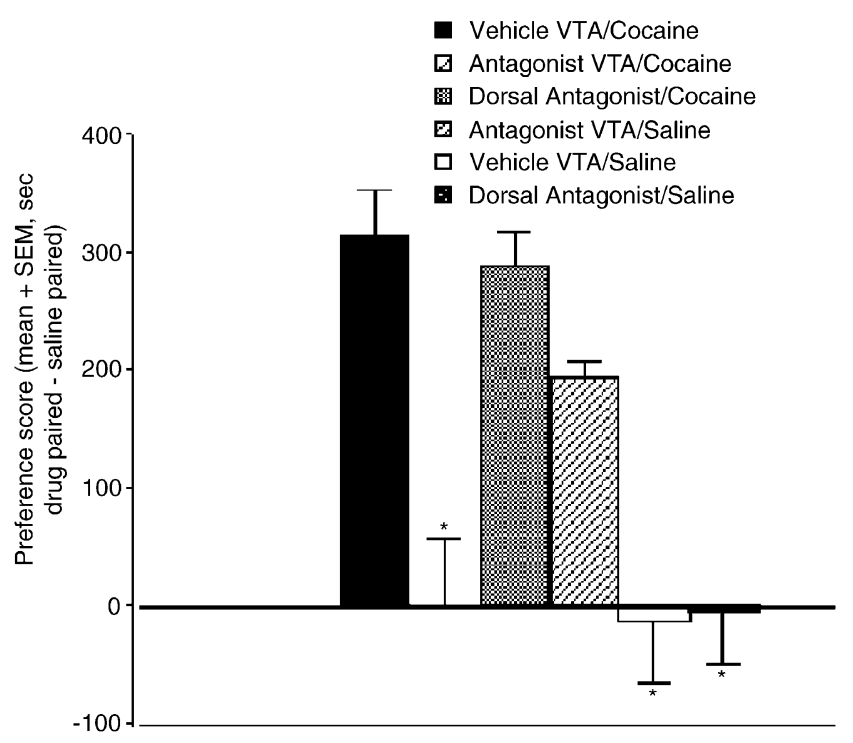

Figure I Preference scores for the cocaine-paired environment expressed as the mean time in seconds spent in the cocaine-paired side (or intracerebral microinjection-paired side for noncocaine-conditioned groups) minus the mean time in seconds spent in the other side on the test day. For VTA groups, only data from animals where injection sites were confirmed to be within the VTA are included. One-way ANOVA on groups yielded $F(5,27)=13.17, p<0.001$. *Significantly different $(p<0.01)$ from Vehicle VTA/Cocaine, Dorsal Antagonist/Cocaine and Antagonist VTA/Saline. 


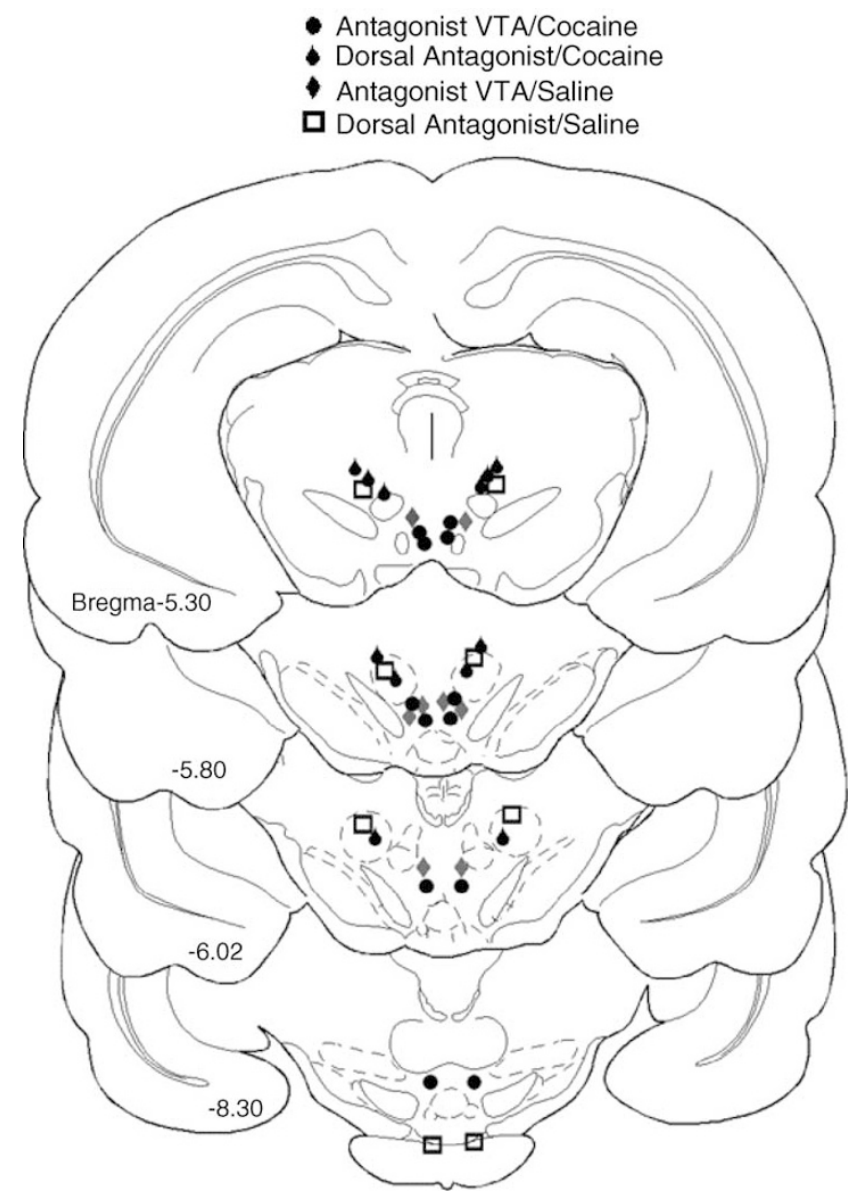

Figure 2 Schematic representations of frontal sections showing the effective (black circle and gray diamond) and ineffective (white square and black drop) sites for glutamate antagonist administration. Injection sites for Vehicle VTA/Cocaine and Vehicle VTA/Saline groups overlapped with those for the other VTA groups and are not plotted. The tissue damage caused by the microinjections was $0.3-0.5 \mathrm{~mm}$ in diameter and was the same across all six groups. Drawings are adapted from Paxinos and Watson (1998).

nonspecific damage caused by the microinjection, because neither vehicle injections into the VTA nor antagonist injections outside the VTA of noncocaine-conditioned rats produced a place preference (Figure 1). Figure 2 shows the locations of effective and ineffective sites for glutamate antagonist administration.

No significant differences were found in locomotor activation among the three groups that received cocaine conditioning, indicating that the antagonists did not disrupt cocaine's locomotor activating effects $(p>0.24$; Figure 3$)$. Animals in the Vehicle VTA/Saline group showed a progressive decrease in locomotor activity over conditioning days that become significantly different on day 3 of conditioning from groups 4 and 6 (which were conditioned with glutamate antagonist administration). The glutamate antagonists alone produced only a small increase in locomotor activity, and this occurred whether they were injected into or outside of the VTA. A previous study reported that AP5 produced a significant increase in locomotor activity when injected into the VTA (Cornish et al, 2001); however, that study used substantially higher doses of AP5 than those given here.

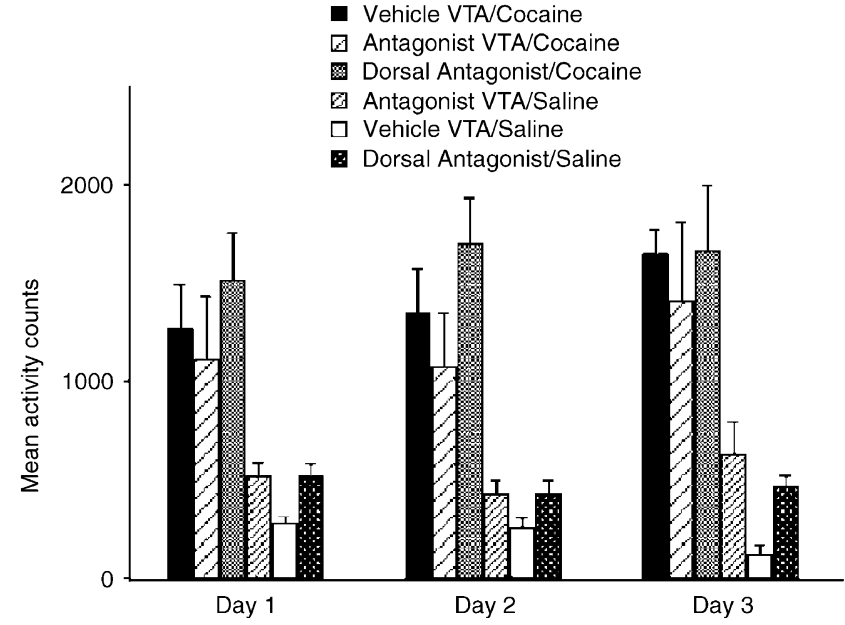

Figure 3 Average photocell counts for each group on the three cocaine conditioning days or intracerebral microinjection days for noncocaineconditioned animals. A comparison of the cocaine-conditioned groups revealed no significant group differences on each of the 3 days. A comparison of the noncocaine-conditioned groups revealed that the Vehicle VTA/Saline group showed significantly less locomotor activity on day 3 relative to the antagonist groups $(F(2, I I)=6.7, p<0.0 I)$.

Our findings show that blockade of glutamate receptors in the VTA prevents the acquisition of a cocaine-associated place preference. Possible explanations for such an action include: (i) decreased cocaine reward, (ii) an aversive action of the antagonists alone, or (iii) decreased ability to learn the association between cocaine and the environment. Overton and Clark (1992) and Georges and Aston-Jones (2002) found that NMDA antagonists administered into the VTA did not decrease basal firing rates of dopamine cells. Furthermore, in vivo microdialysis studies found that AP5 administered into the VTA did not alter extracellular dopamine levels in the VTA's primary terminal fields (ie the nucleus accumbens and prefrontal cortex) (Svensson et al, 1998; Kretschmer, 1999; Fu et al, 2000). It is therefore unlikely that the antagonist effects observed here were a consequence of alterations in dopamine levels.

Our findings illustrate an apparent paradox: that is, how can glutamate antagonists be rewarding when given alone, but also be effective in blocking cocaine reward? Previous work has shown that peripheral or intra-VTA administration of glutamate antagonists is rewarding (Steinpreis et al, 1995; David et al, 1998; Panos et al, 1999) and can increase the rewarding properties of established cocaine reinforcement (Ranaldi et al, 1996; Pierce et al, 1997). Similar treatments, however, have also been shown to block learning reinforced by psychostimulants (Schenk et al, 1993; Cervo and Samanin, 1996; Kim et al, 1996) and to attenuate locomotor sensitization to psychostimulants (Kalivas and Alesdatter, 1993; Wolf and Jeziorski, 1993; Karler et al, 1994; Kim et al, 1996; Cornish et al, 2001). These findings indicate that glutamate antagonists do not alter the learning of cocaine reward because they are aversive (in fact they are rewarding), or because they decrease cocaine reward (they actually increase it if it has already been established). It has been suggested (Cornish $e t$ $a l, 2001)$ that the locomotor activating effects of glutamate antagonists in the VTA are mediated by the inhibition of 
GABA cells that project from the VTA to the forebrain, thereby releasing these areas from inhibition and thus producing locomotor activation and perhaps reinforcement. The rewarding effects of the antagonists in our experiments may use a similar mechanism, while blockade of glutamate receptors in the VTA may prevent acquisition of cocaine conditioning via the blockade of a critical glutamate input that is necessary to associate cocaine with the environmental cues that predict it. Once conditioning has occurred, these glutamate inputs may no longer be necessary to maintain responding for cocaine. The above is somewhat speculative, and more studies are needed to clarify these mechanisms. It is noteworthy, however, that the antagonists did not appear to block learning in general, because animals given the antagonists in the VTA without cocaine learned to prefer the antagonist-paired side.

Together, these data and the present results indicate that the activation of glutamate receptors in the VTA may be essential for learning the association between cocaine and environmental cues that predict cocaine reward. As conditioned effects of cocaine are integral to craving and relapse (Ehrman et al, 1992), the present results reveal neural mechanisms that may be important in cocaine addiction.

\section{ACKNOWLEDGMENTS}

This work was supported by PHS grant DA-06214. We thank Drs Teri Franklin and Julie Blendy for helpful comments on the manuscript and Richard Byrne for technical assistance.

\section{REFERENCES}

Cador M, Bjijou Y, Cailhol S, Stinus L (1999). D-Amphetamineinduced behavioral sensitization: implication of a glutamatergic medial prefrontal cortex-ventral tegmental area innervation. Neuroscience 94: 705-721.

Cervo L, Samanin R (1995). Effects of dopaminergic and glutamatergic receptor antagonists on the acquisition and expression of cocaine conditioning place preference. Brain Res 673: $242-250$.

Cornish JL, Nakamura M, Kalivas PW (2001). Dopamineindependent locomotion following blockade of $N$-methyl-Daspartate receptors in the ventral tegmental area. J Pharmacol Exp Ther 298: 226-233.

David V, Durkin TP, Cazala P (1998). Rewarding effects elicited by the microinjection of either AMPA or NMDA glutamatergic antagonists into the ventral tegmental area revealed by an intracranial self-administration paradigm in mice. Eur J Neurosci 10: 1394-1402.

Ehrman RN, Robbins SJ, Childress AR, O’Brien CP (1992). Conditioned responses to cocaine-related stimuli in cocaine abuse patients. Psychopharmacology (Berl) 107: 523-529.

Fu Y, Matta S, Gao W, Brower V, Sharp B (2000). Systemic nicotine stimulates dopamine release in nucleus accumbens: re-evaluation of the role of $N$-methyl-D-aspartate receptors in the ventral tegmental area. J Pharmacol Exp Ther 294: 458-465.

Georges F, Aston-Jones G (2002). Activation of ventral tegmental area cells by the bed nucleus of the stria terminalis: a novel excitatory amino acid input to midbrain dopamine neurons. $J$ Neurosci 22: 5173-5187.
Hyman SE, Malenka RC (2001). Addiction and the brain: the neurobiology of compulsion and its persistence. Nat Rev Neurosci 2: 695-703.

Kalivas PW, Alesdatter JE (1993). Involvement of NMDA receptor stimulation in the VTA and amygdala in behavioral sensitization to cocaine. J Pharmacol Exp Ther 267: 486-495.

Kalivas PW, Duffy P (1995). $D_{1}$ receptors modulate glutamate transmission in the ventral tegmental area. J Neurosci 15: 53795388.

Karler R, Calder LD, Bedingfield JB (1994). Cocaine behavioral sensitization and the excitatory amino acids. Psychopharmacology (Berl) 115: 305-310.

Kim HS, Park WK, Jang CG, Oh S (1996). Inhibition by MK-801 of cocaine-induced sensitization, conditioned place preference, and dopamine-receptor supersensitivity in mice. Brain Res Bull 40: 201-207.

Kretschmer BD (1999). Modulation of the mesolimbic dopamine system by glutamate: Role of NMDA receptors. J Neurochem 78: 839-848.

Overton P, Clark D (1992). Iontophoretically administered drugs acting at the $N$-methyl-D-aspartate receptor modulate burst firing in A9 dopamine neurons in the rat. Synapse 10: 131-140.

Panos JJ, Rademacher DJ, Renner SL, Steinpreis RE (1999). The rewarding properties of NMDA and MK-801 (dizocilpine) as indexed by the conditioned place preference paradigm. Pharmacol Biochem Behav 64: 591-595.

Parkinson JA, Cardinal RN, Everitt BJ (2000). Limbic corticalventral striatal systems underlying appetitive conditioning. Prog Brain Res 126: 263-285.

Paxinos G, Watson C (1998). The Rat Brain in Stereotaxic Coordinates. Academic Press: San Diego.

Pennartz CM, McNaughton BL, Mulder AB (2000). The glutamate hypothesis of reinforcement learning. Prog Brain Res 126: 231-253.

Pierce RC, Meil WM, Kalivas PW (1997). The NMDA antagonist, dizocilpine, enhances cocaine reinforcement without influencing mesoaccumbens dopamine transmission. Psychopharmacology (Berl) 133: 188-195.

Ranaldi R, French E, Roberts DC (1996). Systemic pretreatment with MK-801 (dizocilpine) increases breaking points for selfadministration of cocaine on a progressive-ratio schedule in rats. Psychopharmacology (Berl) 128: 83-88.

Schenk SS, Valadez AA, Worley CMC, McNamara CC (1993). Blockade of the acquisition of cocaine self-administration by the NMDA antagonist MK-801 (dizocilpine). Behav Pharmacol 4: 652-659.

Steinpreis RE, Kramer MA, Mix KS, Piwowarczyk MC (1995). The effects of MK801 on place conditioning. Neurosci Res 22: 427-430.

Svensson T, Mathe J, Nomikos G, Schilstrom B (1998). Role of excitatory amino acids in the ventral tegmental area for central actions of non-competitive NMDA-receptor antagonists and nicotine. Amino Acids 14: 51-56.

Ungless MA, Whistler JL, Malenka RC, Bonci A (2001). Single cocaine exposure in vivo induces long-term potentiation in dopamine neurons. Nature 411: 583-587.

Wolf ME (1998). The role of excitatory amino acids in behavioral sensitization to psychostimulants. Prog Neurobiol 54: 679-720.

Wolf ME, Jeziorski M (1993). Coadministration of MK-801 with amphetamine, cocaine or morphine prevents rather than transiently masks the development of behavioral sensitization. Brain Res 613: 291-294.

Zhang XF, Hu XT, White FJ, Wolf ME (1997). Increased responsiveness of ventral tegmental area dopamine neurons to glutamate after repeated administration of cocaine or amphetamine is transient and selectively involves AMPA receptors. $J$ Pharmacol Exp Ther 281: 699-706. 